\title{
RISK AND THE UNFAIRNESS OF SOME BEING BETTER OFF AT THE EXPENSE OF OTHERS
}

\author{
Thomas Rowe
}

7 HIS PAPER offers a novel account of how complaints of unfairness arise in risky distributive cases. According to a recently proposed view in distributive ethics, the Competing Claims View, an individual has a claim to a benefit when her well-being is at stake, and the strength of this claim is determined by the expected gain to the individual's well-being, along with how worse off the individual is compared to others. ${ }^{1}$ If an individual is at a lower level of well-being than another, their claim to a given benefit is stronger. On this view, the strength of individuals' claims is a function of their comparative well-being levels. In this paper, I instead argue that competing claims obtain only when a particular relationship holds between the fates of individuals: that one individual's gain is at the expense of another. This is a particular complaint that obtains when the fates of individuals are tied together in such a way that inequality that is to the detriment of the person who is worse off is guaranteed (or likely) to obtain. As such, I argue that complaints of unfairness arise in fewer cases than the Competing Claims View currently states. A purely comparative view is unable to account for this unique complaint of unfairness. I argue that this complaint is not only independently plausible, but can serve as a foundation for a more general account of competing claims complaints.

The paper has three aims. The first is to demonstrate how the type of risk that one is exposed to can make a moral difference to how one should act. There has been little systematic discussion of this question. The second is to outline and defend the plausibility of a unique complaint of unfairness: that sometimes some are better off at the expense of others. The third is to contrast my account of competing claims with that of the recent view of Otsuka, Voorhoeve, and Fleurbaey, and provide a possible extension. They argue that complaints of unfairness arise as a function of the comparative well-being levels of individuals when some are (or are expected to be) worse off than others. The view I offer is different in the respect that it provides an account of competing claims that

1 Voorhoeve and Fleurbaey, "Egalitarianism and the Separateness of Persons," 397. 
is grounded solely in a view about how individuals' interests are related to one another.

Before proceeding, I shall briefly outline what it means for claims to compete. An individual has a claim on a good when her interests are at stake. An individual does not have a claim if her interests are not at stake. Claims of individuals are in competition with one another when they cannot be jointly satisfied. For example, suppose both Cara and David are equally in need of one dose of medicine that will increase their well-being. Francis has one dose of the medicine. Cara and David both have a claim on Francis to be helped. Whereas Emily, who does not need the medicine, does not have a claim on Francis to be helped. Competing claims views remark on how one should act when faced with the competing claims of individuals to some good, or to the avoidance of a burden.

The structure of the paper is as follows. In sections 1 and 2, I argue that when risks are independent, i.e., when the prospects for one person in a gamble do not depend on the prospects of another, it is permissible for a morally motivated decision maker to provide an expected well-being-maximizing alternative, regardless of the number of people involved, and that the potential for outcome inequality does not itself give rise to complaints of unfairness. In section 3 , I argue that in cases where risks are inversely correlated, i.e., when the prospects for one individual have an inverse relation to the prospects of another, a source of individual complaints against a situation in which they are disadvantaged is that some are better off at their expense. This complaint, I argue, should lead us to be averse to inequality in inversely correlated cases. In section 4, I contrast my view with that of the recent competing claims view of Michael Otsuka, Alex Voorhoeve, and Marc Fleurbaey. In section 5, I demonstrate how my account guides action in cases involving certainty, as well as how it respects the distinction between what is called the unity of the individual and the separateness of persons.

1. SINGLE-PERSON CASE AND TWO-PERSON INTRAPERSONAL CASE

Consider the following case:

Single-Person Case: Ann, a young child who is currently in full health, will soon go completely blind through natural causes (utility $=0.65$ ) unless Tessa, a morally motivated stranger, provides one of two available treatments. Treatment $A$ will either, with fifty percent probability, leave Ann blind ( 0.65$)$ or instead, with fifty percent probability, fully cure her (utility $=1$ ); treatment $B$ will restore Ann to partial sight for sure (0.8). (See Table 1.) 
Table 1. Final Utilities for Single-Person Case

\begin{tabular}{l|c|c} 
& S1 (0.5) & S2 (0.5) \\
& Ann & Ann \\
\hline Treatment $A$ & 0.65 & 1 \\
Treatment $B$ & 0.8 & 0.8
\end{tabular}

Before judging this case, I need to clarify the measure of well-being employed. I assume a measure of utility derived from idealized preferences satisfying the Von Neumann-Morgenstern axioms. According to this measure, a prospect has higher expected utility for a person

just in case it would be preferred for that person's sake after rational and calm deliberation with all pertinent information while attending to her self-interest only. (A person's expected utility is just the probability-weighted sum of her utility in each state of the world.) One prospect has the same expected utility as another for a person just in case such deliberation would yield indifference between the two prospects. ${ }^{2}$

Now, supposing only Ann's interests are at stake, which treatment should Tessa select? Treatment $B$ gives Ann a set outcome for sure, but offers a lower expected well-being than treatment $A$. In this case, it is possible to offer the following prudential justification for providing $A$ : "I did the best I could for you given the information I had at the time.” ${ }^{3}$ This provides, I believe, a strong reason for select$\operatorname{ing} A$. Insofar as the individual's interests are considered in isolation from others, there is no countervailing reason to favor $B$. As Michael Otsuka puts it, there are "no interpersonally comparative or otherwise distributive considerations ... that tell in favour of paying heed to anything other than what is in this [person's] rational self-interest." Why, when one is considering this individual's interests alone, ought one to depart from what, given the information available, anyone concerned exclusively with the individual's interests (including the individual herself) would rationally regard as the best one can do for her?

For these reasons, in this paper, I assume the following answer is correct:

Otsuka and Voorhoeve, "Equality versus Priority," 8-9. The measure does not presuppose anything about what the nature of well-being is in itself. For instance, one may think that well-being consists in the satisfaction of preferences or the presence of happiness and absence of suffering. The measure is consistent with a decision maker maximizing whatever it is they take well-being to be. I will use the terms "utility" and "well-being" as synonymous in this article.

3 Voorhoeve and Fleurbaey, "Equality or Priority for Possible People?" 935.

4 Otsuka, "Prioritarianism and the Measure of Utility," 5. 
in Single-Person Case, Tessa should maximize Ann's expected well-being and hence choose $A$. The correctness of this answer has recently been much debated. ${ }^{5}$ I do not revisit the debate here. Instead, I pursue the following, less thoroughly discussed question: How should a view that accepts the premise that one should maximize an individual's expected well-being when one considers her fate in isolation deal with multi-person risky cases, in which the risky alternative that is in the expected interests of each person, taken separately, will generate outcomes in which some end up better off and others worse off than they would under a less risky alternative ${ }^{6}$ This question is important because some who accept my premise hold that in such multi-person-risk cases, each individual has a claim only to what would maximize their expected well-being, and those who end up worse off as a result of the distributor's choice of such an alternative have no complaint. ${ }^{7}$ Against such a view, I argue that within a claims-based framework there can sometimes be reason to select an alternative that does not maximize each person's expected well-being, namely, when choosing what would maximize each person's expected well-being would ensure that some end up better off at the expense of others.

Now consider the following case, inspired by Voorhoeve and Fleurbaey: ${ }^{8}$

Two-Person Intrapersonal Case: This case is identical to the preceding case with the addition of an extra person, Bill, who has partial sight for sure (o.8), no matter what treatment Tessa selects for Ann. Bill's well-being is completely unaffected by Tessa's action. If Tessa selects treatment $A$, then Ann will with fifty percent probability either remain blind ( 0.65$)$ or

5 Otsuka and Voorhoeve ("Why It Matters that Some Are Worse Off than Others") and Otsuka ("Prioritarianism and the Measure of Utility") defend the permissibility of maximizing well-being in the Single-Person Case. McCarthy ("Utilitarianism and Prioritarianism II" and "The Priority View"), Greaves ("Antiprioritarianism"), and Voorhoeve and Fleurbaey ("Priority or Equality for Possible People?") defend the view that one ought to maximize this person's expected well-being. For the contrary view that one is permitted to be risk averse in a person's well-being, see, e.g., Parfit, "Another Defence of the Priority View," 432; and Bovens, "Concerns for the Poorly Off in Ordering Risky Prospects," 404.

6 Many views accept this premise. Most noteworthy are the views defended by Otsuka and Voorhoeve, "Why It Matters that Some Are Worse Off than Others," "Reply to Crisp," and "Equality versus Priority"; Voorhoeve and Fleurbaey, "Egalitarianism and the Separateness of Persons," "Decide as You Would with Full Information!" and "Priority or Equality for Possible People?"; and Frick "Uncertainty and Justifiability to Each Person," 186-91, and "Contractualism and Social Risk," 130-33.

7 For example, Frick, "Uncertainty and Justifiability to Each Person," 144-45, and "Contractualism and Social Risk," $181-88$.

8 Voorhoeve and Fleurbaey, "Egalitarianism and the Separateness of Persons," 386. 
instead, with fifty percent probability, be fully cured (1); treatment $B$ will restore Ann to partial sight for sure (0.8). (See Table 2.)

Table 2. Final Utilities for Two-Person Intrapersonal Case

\begin{tabular}{l|cc|cc} 
& \multicolumn{2}{|c|}{ S1 (0.5) } & \multicolumn{2}{c}{ S2 (0.5) } \\
& Ann & Bill & Ann & Bill \\
\hline Treatment $A$ & 0.65 & 0.8 & 1 & 0.8 \\
Treatment $B$ & 0.8 & 0.8 & 0.8 & 0.8
\end{tabular}

In this case, Tessa ought to, in my view, select $A$. Only Ann's interests are at stake in this case, just like in Single-Person Case. Just as it was reasonable to select a treatment in Single-Person Case to maximize Ann's expected well-being, it should also be the case here. The only difference to the structure of the example is that now there is an extra individual, Bill, who is completely unaffected by Tessa's decision. If we believe that only people who have their well-being at stake in a gamble have a complaint, or potential complaint, against the actions that a decision maker will take, then Tessa ought to select $A$. To lend support to this idea, an interpretation of contractualism, the Complaint Model, states that "a person's complaint against a principle must have to do with its effects on him or her, and someone can reasonably reject a principle if there is some alternative to which no other person has a complaint that is as strong." The absence of any effects on Bill from Tessa's action means that Bill does not have a complaint against the provision of $A$. This captures an important feature of the separateness of persons. The separateness of persons establishes that, because individuals lead separate lives, it is inappropriate to balance benefits and burdens across individuals as if they were a super-individual. A present or possible burden for an individual can be compensated by a future or possible benefit, whereas a burden to one individual cannot straightforwardly be compensated by giving a benefit to another person. The provision of treatment $A$ only affects Ann's interests, and does not interfere with the interests of Bill.

One way to argue against the selection of $A$ in this case is to claim that the morally motivated decision maker ought to care about the fact that there will be inequality if $A$ is selected. For instance, there may be a brute luck egalitarian reason to favor the selection of $B$, for this ensures that both Ann and Bill will have a well-being level of 0.8 . Brute luck egalitarians believe that "it is bad, or objectionable, to some extent—because unfair-for some to be worse off than others

9 Scanlon, What We Owe to Each Other, 229. However, Scanlon also argues that there may be considerations other than well-being that may lead to grounds for complaints, such as complaints of unfairness. 
through no fault or choice of their own." ${ }^{10}$ Even if Ann and Bill were on separate continents and had absolutely no relationship with one another, inequality between them would be bad to the extent that it did not follow from a choice of theirs.

This view can be defended with an appeal to impersonal value. Perhaps brute luck equality is impersonally valuable. My response is that, although it may be granted that brute luck inequality can sometimes provide reasons for action, it is unreasonable for such impersonal considerations to outweigh the individual reasons that Ann possesses in favor of the selection of $A$ in this particular case. Given that only Ann's interests are at stake in this case, nothing other than a concern for Ann's rational self-interest should determine what treatment ought to be selected. ${ }^{11}$ If $A$ is selected then there will be outcome inequality for sure, but there will be no reasonable complaints against this.

Ittay Nissan-Rozen has argued that a distributor has a pro tanto reason to discard impersonal reasons when deciding what reasons to take into account when acting in a risky distributive case. ${ }^{12}$ Nissan-Rozen appeals to the Kantian demand to treat individuals as ends in themselves and not as mere means. The impersonal reason of equality has nothing to do with Ann's well-being. By selecting an alternative in line with this impersonal reason when only Ann's interests are at stake, "the distributor treats the [impersonal reason] itself ... as the end of the act of weighing it; and so, by weighing [the impersonal reason], the distributor treats [Ann] as a means to an end: she treats her as a means for the end of satisfying [the impersonal reason]." ${ }^{13}$ As such, there is further reason to be skeptical of the claim that in cases where individuals have claims grounded in their (expected) well-being, one ought to sometimes act in accordance with impersonal reasons. Although impersonal reasons may feature in the deliberations of an agent, they should not veto the individual reasons of those who stand to have their interests affected.

The inequality present in Two-Person Intrapersonal Case does not provide a sufficient reason to favor treatment $B$. My view is that inequality is necessary but not sufficient for a complaint of unfairness in risky cases. The presence of inequality does not guarantee a complaint of unfairness.

11 As such, it may be the case that brute-luck inequality can provide reason for action, but such a consideration fails to outweigh the considerations in favor of selecting what is best for Ann, since only Ann's well-being is at stake in Tessa's choice.

Nissan-Rozen, "How to Be an Ex-Post Egalitarian and an Ex-Ante Paretian."

Nissan-Rozen, "How to Be an Ex-Post Egalitarian and an Ex-Ante Paretian," 554. 
I now consider a case involving two individuals, where the well-being of both is at stake.

Fully Independent Risk Case: Two children, Ann and Bill, will soon go completely blind through natural causes (utility $=0.65$ ) unless Tessa, a morally motivated stranger, provides one of four possible treatment alternatives. She can give treatment $A$ to Ann and treatment $B$ to Bill or vice versa, or she can give both individuals treatment $A$ or both treatment $B$. Ann's and Bill's outcomes under the treatments are statistically independent of each other. (See Table 3.)

Table 3. Final Utilities for Fully Independent Risk Case

\begin{tabular}{l|cc|cc|cc|cc} 
& \multicolumn{2}{|c|}{$\mathrm{s} 1(0.25)$} & \multicolumn{2}{c|}{$\mathrm{s} 2(0.25)$} & \multicolumn{2}{c|}{$\mathrm{s} 3(0.25)$} & \multicolumn{2}{c}{$\mathrm{s} 4(0.25)$} \\
& Ann & Bill & Ann & Bill & Ann & Bill & Ann & Bill \\
\hline $\begin{array}{l}\text { Ann: } A \\
\text { Bill: } A\end{array}$ & 0.65 & 1 & 1 & 0.65 & 0.65 & 0.65 & 1 & 1 \\
\hline $\begin{array}{l}\text { Ann: } B \\
\text { Bill: } B\end{array}$ & 0.8 & 0.8 & 0.8 & 0.8 & 0.8 & 0.8 & 0.8 & 0.8 \\
\hline $\begin{array}{l}\text { Ann: } A \\
\text { Bill: } B\end{array}$ & 0.65 & 0.8 & 1 & 0.8 & 0.65 & 0.8 & 1 & 0.8 \\
\hline $\begin{array}{l}\text { Ann: } B \\
\text { Bill: } A\end{array}$ & 0.8 & 1 & 0.8 & 0.65 & 0.8 & 0.65 & 0.8 & 1
\end{tabular}

Tessa ought to select $A$ for both individuals in this case. The same reasoning that supported the selection of $A$ in the preceding cases supports the same selection in Fully Independent Case. Ann's and Bill's futures are in every sense independent from one another, since (i) it is possible to offer either treatment to each individual independently of which treatment is offered to the other, and (ii) under each alternative any risks they face are independent. This implies that the well-being of Ann and Bill is separate in the same way that it is in Two-Person Intrapersonal Case. By this I mean their potential futures are not linked together: the well-being value of each individual is not causally dependent on the well-being values of other individuals. For example, if Tessa chooses $A$ and Ann ends up with a particular level of well-being, then this has no bearing on what level of well-being Bill ends up with.

It is important to distinguish my use of "separateness" here from what is known in welfare economics as "additive separability." If one tries to order dis- 
tinct distributions of individuals' well-being, one may believe that such orderings are "additively separable," which contains the thought that the moral value of "each person's well-being should be evaluated independently of other people's wellbeing." ${ }^{14}$ I do not endorse this idea of additive separability. As I argue below, in determining the moral value of individuals' well-being, comparisons between their well-being matter just in case their fates are "tied together" in a particular manner. Rather than additive separability, I am instead endorsing an account of separability that is consistent with the separateness of persons, in that it tracks cases in which these futures are thoroughly independent, or unlinked.

In Fully Independent Case (Table 3 ) there is the possibility of inequality between Ann and Bill if Tessa chooses $A$ for one or both of them. In Two-Person Intrapersonal Case (Table 2), inequality was certain to occur if $A$ was selected, but this did not form the basis of individual complaints. How should Tessa accommodate the possibility of outcome inequality given that the interests of both individuals are now at stake? I think that, again, the potential inequality if $A$ is selected for one or both of them is no basis for individual claims against selecting $A$. What is of importance in this case, as in the preceding two cases, is the separateness of Ann's and Bill's prospects. The potential futures of Ann are distinct from Bill's potential futures; moreover, nothing decided by Tessa about Ann's future affects Bill's fate, nor does anything that happens by chance to Ann affect how Bill ends up, and vice versa. In this regard, the expectably best treatment for Ann leaves Bill's well-being unaffected, and the expectably best treatment for Bill leaves Ann's well-being unaffected. Furthermore, there is a decisive reason to select treatment $A$ for both Ann and Bill given the strength of the prudential justification that can be offered to both, based on the fact that the prudential justification appeals to these unified potential futures of each person.

One could object to the selection of $A$ for both individuals by arguing that, while there is no complaint against inequality per se, this is a case in which, if we choose $A$ for both, some may end up better off and others worse off than they might as a consequence of our choices, so that there may be competing claims $e x$ post between the better and the worse off. And when there are such competing claims, whoever will end up worse off has a claim to an alternative in which they would have ended up better off (so to be given $B$ in this case). ${ }^{15}$

Recall that an individual has a claim only if their interests are stake. For example, in Two-Person Intrapersonal Case (Table 2) there is only a claim on Ann's behalf since Bill's interests are not at stake. In Fully Independent Case (Table 3)

14 Broome, "Equality versus Priority," 220-21.

15 Such reasoning is suggested by Voorhoeve and Fleurbaey, "Priority or Equality for Possible People?" $10-11$. 
the interests of both Ann and Bill are at stake, but they are not in competition because they do not conflict ex ante, nor, despite the possibility of inequality, can they conflict ex post, as I now explain.

If $\mathrm{s} 1$ obtains, then it is best for Ann that $B$ is selected. Selecting the best for Ann $(B)$ does not preclude selecting the best for Bill $(A)$, since it is possible to give $B$ to Ann and $A$ to Bill. This is because of the separateness of Ann's and Bill's prospects. Nothing that is decided about Ann's fate affects the fate of Bill. Similarly, the treatments affect each individual independently. There is therefore no ex post conflict of interest if s1 obtains. Analogous reasoning establishes the same for every other state of the world. There is therefore no conflict of interest ex post in any state of the world. Since there is no conflict of interest, I conclude that Tessa should simply select what is expectably best for each, which is $A$.

Now consider the following modification to the preceding case:

Modified Independent Risk Case: The setup of this case is the same as before. However, due to technical limitations, Tessa can either provide both with treatment $A$ or both with $B$, but cannot offer one of them $A$ and the other $B$. (The case is described in Table 4.)

Table 4. Final Utilities for Modified Independent Risk Case

\begin{tabular}{l|cc|cc|cc|cc} 
& \multicolumn{2}{|c|}{$\mathrm{S} 1(0.25)$} & \multicolumn{2}{|c|}{$\mathrm{S2}(0.25)$} & \multicolumn{2}{c|}{$\mathrm{s} 3(0.25)$} & \multicolumn{2}{c}{$\mathrm{s} 4(0.25)$} \\
& Ann & Bill & Ann & Bill & Ann & Bill & Ann & Bill \\
\hline Both get $A$ & 0.65 & 1 & 1 & 0.65 & 0.65 & 0.65 & 1 & 1 \\
Both get $B$ & 0.8 & 0.8 & 0.8 & 0.8 & 0.8 & 0.8 & 0.8 & 0.8
\end{tabular}

Does this modification change anything regarding what Tessa ought to do? One may observe that, as visible in the table above, there is a fifty percent chance that there will be a conflict of interest in final utilities, and that there are therefore competing interests ex post. Treatment $A$ is rationally preferred by both individuals, but this choice is, in states of the world $s_{1}$ and $s 2$, better than $B$ for one person but worse than $B$ for another. Suppose, for instance, that $\mathbf{s} 2$ obtains. Giving $B$ to both is best for Ann, but giving $A$ to both is best for Bill. Their ex post interests therefore conflict, because both must receive the same treatment.

However, this potential ex post conflict of interest in Modified Independent Risk Case does not make a difference to what Tessa ought to do. Although it is not possible to provide a different treatment to each individual, the treatments affect each individual separately, in the sense that, if one chooses the risky treatment for both, the fact that one is well-off does not imply (or increase the chance that) the other is badly off. 
Moreover, $A$ would have been selected individually if it was possible to do so, as in Fully Independent Case (Table 3). The mere fact that options are removed that one would not select anyway should not make a difference to what one ought to do. Suppose that an individual is faced with a number of options, and that one alternative is permissibly chosen from these options. Suppose that we now shrink this set of options by removing one of the unchosen alternatives. The permissible alternative ought to remain permissible in this subset. This is the property of "basic contraction consistency." ${ }^{16}$ If giving $A$ to both is permissible in Fully Independent Risk Case (Table 3), then it should also be permissible in Modified Independent Risk Case (Table 4), which contains a subset of the alternatives in the former case.

I have argued that there are no complaints that give us reason to go against the recommendation to provide treatment $A$ in these cases. The pattern of inequality arising in Two-Person Intrapersonal Case (Table 2) was not sufficient grounds for a complaint on behalf of Bill as he did not have a claim against Tessa because his interests were not affected by her action. Against the idea that the potential inequality in Fully Independent Risk Case (Table 3 ) if $A$ were given to both should be of concern, I argued that this inequality need not be of concern because this is not a case of competing interests (neither ex ante nor ex post) between a better-off and worse-off person. I then appealed to both the independence of Ann's and Bill's fates to argue that in Modified Independent Risk Case (Table 4) Tessa ought to still give $A$ to both.

\section{INVERSELY CORRELATED RISKS AND THE COMPLAINT} THAT SOME ARE BETTER OFF AT THE EXPENSE OF OTHERS

In this section, I consider how the view I am defending handles conflict of interest cases and arrive at a characterization of when competing claims obtain. I argue that there is an important moral difference between independent and inversely correlated risks. In the case of inversely correlated risks, the complaint of unfairness does not derive from the outcome inequality itself, but rather the fact that one is better off at the expense of another. I argue that this complaint ought to be included in a plausible account of competing claims. I argue that in cases of independent risks this particular complaint does not arise, and that this is so even if the same pattern of inequality arises as it does in an inversely correlated case.

Consider the following: 
Inversely Correlated Case: Ann and Bill will both soon, through natural causes, go completely blind unless Tessa administers one of two treatments. Treatment $A$ will either, with fifty percent probability, cause Ann to go blind (0.65) and Bill to retain full vision (1), or instead, with fifty percent probability, cause Bill to go blind and Ann to retain full vision. Treatment $B$ will restore both Ann and Bill to partial sight for sure (0.8). (See Table 5.)

Table 5. Final Utilities for Inversely Correlated Case

\begin{tabular}{l|cc|cc} 
& \multicolumn{2}{|c|}{ s1 (0.5) } & \multicolumn{2}{c}{ S2 (0.5) } \\
& Ann & Bill & Ann & Bill \\
\hline Treatment $A$ & 0.65 & 1 & 1 & 0.65 \\
Treatment $B$ & 0.8 & 0.8 & 0.8 & 0.8
\end{tabular}

Which treatment should Tessa choose? There are reasons that pull in different directions. First, there are considerations in favor of $A$ due to the presence of a prudential justification to Ann and Bill, since $A$ maximizes both Ann's and Bill's expected well-being. Second, there are considerations against the selection of $A$, due to the fact that (I shall argue) one will be better off at the expense of another. On balance, I argue that Tessa ought to select $B$ in this case.

In this case, there will always be a conflict of interest ex post, whereas in Two-Person Intrapersonal Case (Table 2), although there was inequality for certain there was no conflict of interest. There will be a competing claims complaint in Inversely Correlated Case (Table 5) on behalf of whoever turns out to be worse off. This speaks in favor of selecting $B .{ }^{17}$ One important consideration is that the identity of the individual who would be better off if $A$ were selected and that of who is worse off is not known in this case-all that is known is that one individual will be in each position. This is important because there is a moral distinction between placeholders and persons. As Johann Frick argues, it makes a difference to the type of justification that can be given to each person in this case: "contractualist justification is owed to persons, with determinate identities and interests, not placeholders in a pattern of outcomes." ${ }^{18}$ We might think that, because we do not know who will be better off and who will be worse off, Tessa could justify the selection of $A$ to both because she does not know the

In structurally analogous cases, others agree with the selection of $B$. For example, Otsuka, "Prioritarianism and the Separateness of Persons," 373-74; Otsuka and Voorhoeve, "Why It Matters that Some Are Worse Off than Others," 173-74; and Voorhoeve and Fleurbaey, "Decide as You Would with Full Information!" 118-19.

Frick, "Uncertainty and Justifiability to Each Person," 141. 
identity of who will be better off. To see how this might work, consider Frick's argument in this case:

[Ann] and Bill, if they are self-interested [and competent choosers], would not want [Tessa] to choose $[B]$. It is in both persons' ex ante interest that we take a gamble on their behalf by choosing $[A]$. The question is: to what extent could either [Ann] or Bill complain of "outcome unfairness" when any outcome inequality under $[A]$ results from having forgone an option, in line with their own self-interest, that would have satisfied both of their claims to a significant extent and produced no inequality? We might think that, by receiving $[A],[$ Ann $]$ and Bill "exchanged" their claim to the significant benefit that they could have gotten from $[B]$ in return for the chance of getting an even greater good-a gamble that was in both persons' self-interest. It is not clear that, having made this exchange, either $[\mathrm{Ann}]$ or Bill is left with any valid complaint of unfairness if $[A]$ does not turn out in [their] favour. ${ }^{19}$

Contrary to Frick, I think that the individuals do possess a valid complaint of unfairness. For the complaint of unfairness in this case does not arise merely from the pattern of inequality that results, but rather from the fact that, inevitably, someone is benefitted by the other's misfortune. In this case, the fact that it is not possible for both individuals to be simultaneously better off (or worse off) means that it is possible for a compliant to arise on behalf of the worse off: "someone else is better off at my expense." The strength of this complaint is determined by the degree to which risks are inversely correlated. The complaint is at maximal strength when the risks are perfectly inversely correlated, as in Inversely Correlated Case, and would be nonexistent in independent risk cases. But for cases that involve a mixture of the two risks, where the risk is partly inversely correlated, the strength of the complaint weakens.

This is a distinct complaint of unfairness that an individual can raise irrespective of any judgments about the pattern of inequality. This complaint of unfairness arises when one is worse off as a causal flip side of someone else benefitting. This view also captures the following two ways in which one can be worse off than another: when one is made worse off in order to benefit another, and when one is made worse off as a side effect of benefiting another. In both of these cases one is made worse off as a causal flip side of another being benefitted. One would not be benefitted were it not for another being burdened. ${ }^{20}$

Frick, "Uncertainty and Justifiability to Each Person," 144-45.

An interesting feature of inversely correlated risks is the role that consent might play in legitimatizing exposure to such risks. We might think that having one's fate tied to another's 
Part of the grounding for this distinct claim of unfairness comes from the separateness of persons. When an individual's potential futures involve another's interests, a claim of unfairness may arise if the individuals' interests are linked in such a way that inequality may arise. The potential complaint of unfairness can be further illustrated by the following example. Following the structure of Single-Person Case (Table 1), suppose Ann ends up badly off after Tessa selects treatment $A$ on her behalf. If Ann then learned that the gamble was one in which the potential to gain was hers but that the gain in fact failed to materialize, then Ann may see her position as justified as she had a large enough chance of being better off to make the gamble in her interest. But if Ann were to then learn that the flip side of her loss was in fact a gain to another person, she may well think that the other person is better off at her expense, since if she were not worse off, he would not be better off. Suppose that in Single-Person Case, Ann ends up badly off. In this case the potential alternative future of Ann's, where she could have been better off, evanesces when it fails to materialize for her. Suppose, now, that Ann ends up badly off in Inversely Correlated Case. Instead of Ann's potential future evanescing where she could have been better off (as in Single-Person Case), it instead falls to another individual, Bill. There is an important moral difference between these two states of affairs. This is because it is not possible in Inversely Correlated Case for both Ann and Bill to be simultaneously better off. Only one person can be better off, whereas in the independent risk cases it is possible for both to be better off. ${ }^{21}$

arbitrarily is unjust, whereas if one chooses to tie one's fate to another's then this is permissible. For example, Ann and Bill may choose to go to a casino where all of their payoffs are dependent (if Ann wins, then Bill loses and vice versa) or to a casino where all their payoffs are independent of one another. This would be due to the preferences that Ann and Bill have for risk. Whereas if one entered a casino with the intention of gambling alone (with payoffs independent of others') then one may object if one's gamble turned out to be tied up with another. If Ann loses a gamble then it might appear that Ann lost at the expense of Bill. But whether we think it is permissible that one's fate is inversely correlated with the fate of another may come down to whether the inverse correlation is voluntary. Here, I consider only risks that are nonvoluntary, because neither Ann nor Bill can make a choice for which they are responsible_-only Tessa can.

21 The possibility that all could be better off speaks in favor of exposure to independent risks over inversely correlated risks. Bovens ("The Ethics of Making Risky Decisions for Others") considers cases where one may be willing to take on a risk for the chance that all will be well, rather than have a scenario where some will lose out for sure. Independent risks may be favored by decision makers who want a chance for all to fare well, rather than inversely correlated risks, where some will definitely fare worse off than others. Rowe and Voorhoeve ("Egalitarianism under Severe Uncertainty," 260-61) consider a case where there is a chance that both individuals will either sink or swim together, like in the Perfectly Correlated Case, below. A correlated risk that includes the potential for a catastrophe, where all individuals 
An independent grounding for the distinct claim of unfairness is how inversely correlated risks have a negative effect on relational values such as solidarity. Having one's fate tied with another such that when one loses another wins modifies social relations in a way that we may have reason to regret. We prefer that we are not thrusted into essentially competitive situations where the gains to some come at the expense of others. Gaining at the expense of others is at odds with the value of solidarity. Frances Kamm defines solidarity as the "desire for all to get something."22 This is expressed when everybody is put in the same boat, so to speak. Solidarity is not infringed when everyone is in the same predicament, but it is infringed when some gain at the expense of others. To illustrate, consider the following case:

Perfectly Correlated Case: This has the same setup as Single-Person Case, with the exception that there are now one hundred individuals who will either, with fifty percent probability, all go blind (o.65) if $A$ is selected, or instead, with fifty percent probability, all will retain full vision (1).

If $A$ is selected then there will always be equality between the one hundred. Either all will be blind or all will retain full vision. Furthermore, since everyone is in the same predicament, there is no infringement of solidarity between the one hundred. The fates of each are "tied together," but not in a way that leads one to gain at the expense of others. The infringement of solidarity highlights the relational nature of the complaint of unfairness that some are better off at the expense of others.

The relational aspect of the complaint can be further brought out by considering Hugh Lazenby's account of the "uniqueness of experience." 23 This is "the fact that a person experiences only the one life she actually leads, and not the other possible lives that there was a probabilistic chance that she might have had." ${ }^{24}$ Suppose that a faraway potential benefactor flips a coin, and if the coin

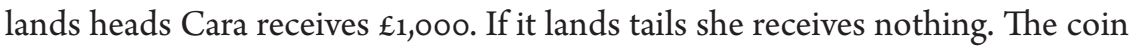
lands tails. It seems that Cara has gained nothing of concrete value since she only experiences what she actually has. What I think does matter however, is whether other individuals experience the other possible futures that were open to her at her expense. If it was the case that when the coin landed tails the $£ 1,000$

fare as badly off as possible, may provide an extra reason against selecting that particular alternative. This is especially the case if each individual could have fared better off under an alternative course of action.

22 Kamm, Morality, Mortality Volume I, 125.

23 Lazenby, "Broome on Fairness and Lotteries," 339-41.

24 Lazenby, "Broome on Fairness and Lotteries," 340. 
went to another person, David, he is better off than her at her expense, since this potential future of hers (having $£ 1,000$ ) goes to David, while Cara gets nothing. Although I do not experience the possible life that I could have led, the fact that another individual does experience that life while I do not makes a moral difference to the complaints of unfairness that I can potentially raise.

The force of the complaint is a function of how worse off one would have been had another alternative been selected instead. For example, in the coin-flip example, Cara is left worse off than David after the coin is flipped. But Cara is not left worse off than she would otherwise have been, since had the coin not been flipped she would likewise have received nothing. Whereas, in Inversely Correlated Risk Case the loser of the gamble if $A$ is selected is left worse off than they would have been if the alternative $B$ were selected instead. Although the fates of individuals are tied together in both cases, the objectionableness of this entangling increases in line with the degree that one would be worse off than one otherwise would have been. It does so because although an individual may have lost a gamble at the expense of another winning the gamble, there is not a diminution in their level of well-being. When there is such a diminution of well-being compared to an alternative that does not diminish that individual's well-being, the case for selecting the alternative is strengthened. As a result, the complaint of the individual for not selecting that alternative strengthens.

A challenge to this view is as follows. Suppose Tessa believes she is facing the decision in Single-Person Case, believing that Ann is exposed to an independent risk if treatment $A$ is selected. Tessa is about to select $A$. A person then comes along and says, "Wait! Are you sure that the risk is fully independent? Might it not in fact be inversely correlated?" One might argue that it does not make any difference to what Tessa ought to do in this case, and that she would have no reason to find out whether the risk is in fact inversely correlated. ${ }^{25}$ Surely, it may be argued, it is enough that this treatment is in Ann's expected best interests. In response, I claim that it does matter whether the risk that Ann is exposed to is either an independent or an inversely correlated risk. It matters because it determines the sort of complaint that might be available to Ann (if at all) if she ends up badly off. Now suppose that treatment $A$ is selected in this case and Ann ends up badly off. On her way home she discovers someone who was in fact a beneficiary of Tessa's decision to select treatment A. Now Ann has grounds for complaint since someone is better off at her expense. ${ }^{26}$ In this scenario it may be

This ground for complaint can be distinguished from envy. To illustrate, suppose a scarce good is distributed either by pulling straws (correlated risk) or by each person flipping a coin (independent risk). It might be said that the person who does not receive the good 
objected that the fact that there is now a beneficiary ought to count in favor of the justifiability of an action and not against it. But the fact that there turned out to be a beneficiary is not in itself something that counts against selecting treatment $A$. Instead, it is the causal relationship between the benefit and the burden that matters: that one could only have the benefit if another had the burden.

The discussion so far leads to the following characterization of when individuals have competing claims:

Competing Claims: Competing claims obtain if and only if individuals' interests conflict ex ante or, ex post, some might be better off at the expense of another. That is to say, either ex ante, all alternatives that are best for one individual are worse for another individual, or there is a chance that, ex post, all alternatives that are best for one individual involve that individual being better off at the expense of another.

This view can explain why Tessa ought to select $B$ in Inversely Correlated Case. In Inversely Correlated Case there will always be competing claims as the interests of the better off will always conflict with the interests of the worse off. This is a decisive reason to select $B$ in this case. This view also explains why there are no competing claims in Two-Person Intrapersonal Case and the independent risk cases. All of the alternatives that are best for one individual do not involve that individual being better off at the expense of another. There is no conflict of interest ex post in these cases.

\section{OTSUKA, VOORHOEVE, AND FLEURBAEY'S COMPETING CLAIMS VIEW}

This view can be contrasted with Otsuka, Voorhoeve, and Fleurbaey's account of competing claims. ${ }^{27}$ According to these authors, an individual has a claim to

after pulling straws is merely envious that they lost out on the gamble and another person won. I do not think that this would be plain envy, since this type of envy would obtain had they lost the coin flip, too. The sentiment after losing out in pulling straws is that the mechanism is such that their losing is tantamount to another winning. This complaint is directed at the structure of the mechanism, and reveals a source of a unique complaint that is distinguishable from mere envy at discovering that another person has fared better when you fared worse. I thank an anonymous reviewer for raising this point.

27 It is also possible to distinguish my view from the Restricted Prioritarianism view outlined by Williams, “The Priority View Bites the Dust?" In intrapersonal cases, individuals have a claim on the alternative that maximizes their expected utility. However, in interpersonal cases individuals have claims to be benefited that become stronger as their absolute position worsens. Because I do not explicitly engage with prioritarianism in this paper, I leave out a detailed examination of this view. Lange ("Restricted Prioritarianism or Competing 
some benefit if and only if their interests are at stake, where the strength of this claim is determined by

(i) her potential gain in well-being; and

(ii) her level of well-being relative to others with whom her interests conflict. $^{28}$

As it stands, this view would state that competing claims exist in the independent risk cases discussed in section 2, because there is an ex post conflict of interest between the winners and the losers of the gambles. ${ }^{29}$ Although the claims of the winners and the losers of the gambles in these cases are in competition with one another, in the respect that some are better off than others, it is not the case that the interests of each person are in conflict with one another in a way specified by my view.

Under my proposal, competing claims do not merely obtain when the interests of individuals are in competition with one another, but rather only when some might be better off at the expense of another. To this extent, my view differs from Otsuka, Voorhoeve, and Fleurbaey's view, by specifying when precisely competing claims obtain. The Competing Claims View, as it stands, allows for more unfairness complaints than I think are warranted. This is because complaints arise as a result of (expected) differences in levels of well-being between individuals, rather than how the fates of individuals are related to one another. My view limits the scope of cases where competing claims obtain to those cases where some are made better off at the expense of others. Given my arguments in sections 1 to 3 , there is reason to believe that inequality itself does not determine the existence of complaints, but rather that complaints of unfairness are a function of how one's interests relate to others. The view I have defended partially detaches complaints from mere considerations of comparative levels of well-being, as it is how one's interests relate to others that potentially generates complaints.

Although inequality is necessary for a complaint of unfairness, it is not sufficient. The view I have defended provides a sufficient condition for a complaint

Claims?"), however, examines the differences between Restricted Prioritarianism and the competing claims view of Otsuka, Voorhoeve, and Fleurbaey.

This specification of the view is from Lange, "Restricted Prioritarianism or Competing Claims?" 140. Voorhoeve and Fleurbaey also provide a similar outline ("Egalitarianism and the Separateness of Persons," 397).

29 One might argue that complaints can be discounted by the probability that inequality would occur. For example, in Fully Independent Risk Case (Table 3), inequality occurs in half of the states of the world if treatment $\mathrm{A}$ is given to both, and as such one's competing claims complaint at ending up worse off than another could be discounted by its improbability. Nevertheless, a competing claims complaint still exists. 
of unfairness in risky distributive cases. Although the view can stand alone as an independent theory of competing claims, it would in principle be possible for defenders of Otsuka, Voorhoeve, and Fleurbaey's competing claims approach to modify the view by adding "the fact that some are better off at the expense of others" as a third condition. However, doing so will come at a cost, since the range of cases where competing claims obtain will shrink to only those cases where one person's gain is the causal flip side of another person's loss.

The difference between the views can be further highlighted by considering the following case inspired by Roger Crisp: ${ }^{30}$

Many-Person Independent Risk Case: This is the same as Fully Independent Case, except that there are now five hundred people.

What one can infer from this case is that it is extremely likely that there will be outcome inequality if Tessa chooses $A$-indeed, that the pattern of outcome inequality will be similar to the inequality in Inversely Correlated Case, in that roughly half will be well off and half badly off. It might be said that the law of large numbers does the work that inverse correlation does in Inversely Correlated Case. ${ }^{31}$ Crisp argues that, in this case, one ought to select $B$ for each child for prioritarian reasons. ${ }^{32}$ In other words, applied to this case, it is more important to improve a person's well-being from 0.65 to 0.8 than from 0.8 to 1 . Otsuka and Voorhoeve agree with this conclusion, but for egalitarian reasons. ${ }^{33}$ Contrary to these authors, however, I have argued that independent risk cases possess an important moral feature. If inequality obtains, individuals are not worse off to another's benefit. Therefore, there are no competing claims. Even if the pattern of inequality turns out to be identical in Many-Person Independent Risk Case and Inversely Correlated Risk Case (Table 5), individuals will not be better off at the expense of others in the former but will be in the latter. In response, it could be argued that there will be a competing claims complaint in Independent Risk Case, albeit discounted by the probability that inequality will arise. I have demonstrated, however, that competing claims complaints do not arise in independent risk cases.

\section{COMPETING CLAIMS AND THE SEPARATENESS OF PERSONS}

In this section I consider how the competing claims account handles conflict

Crisp, “In Defence of the Priority View," 107.

Otsuka and Voorhoeve, "Reply to Crisp," 113. 
of interest cases under certainty. I will thereby expand the part of the account that sees the badness of inequality in conflict of interest cases being the fact that some are worse off at the expense of others. I then demonstrate how the view reflects a concern for the separateness of persons.

Consider the following case:

Certainty Case: Ann will develop partial sight (o.8) and Bill will go wholly blind (0.65). Tessa can either give treatment $A$, which moves Ann from her partial sight to full health (1), or provide treatment $B$, which moves Bill from complete blindness to partial sight (o.8). (See Table 6.)

Table 6. Final Utilities for Certainty Case

\begin{tabular}{l|cc} 
& \multicolumn{2}{|c}{ S1 } \\
& Ann & Bill \\
\hline Treatment $A$ & 1 & 0.65 \\
Treatment $B$ & 0.8 & 0.8
\end{tabular}

I submit that Tessa ought to select $B$, since there are competing claims in this case. The interests of Ann and Bill are in conflict, and providing $A$ will only be in the best interests of Ann and contrary to the interests of Bill, who can never be better off than Ann. Ann starts off better off than Bill, and selecting $A$ will further benefit Ann at Bill's expense. On the view I am proposing, this makes $A$ especially problematic. In such cases of certainty the competing claims account has maximal force. Both individuals' claims are in conflict both $e x$ ante and $e x$ post; it is never possible to have a joint satisfaction of claims. There is no greater value of chances that could outweigh the claim of unfairness in this case, unlike in Inversely Correlated Case (Table 5). How could Tessa justify the selection of $A$ to Bill when he is much worse off than Ann, this treatment would never be in his best interests, and he could gain nearly as much as Ann could if he were treated instead? $?^{34}$

Throughout, I have appealed to respect for the difference between the unity of the individual and the separateness of persons in order to justify my view. According to the "unity of the individual" an individual's life possesses a unity that makes it appropriate to balance benefits and burdens that accrue to her for her sake, but inappropriate to balance benefits to some with only costs to others. ${ }^{35}$ This helps justify the selection of the utility-maximizing treatment in Single-Person Case since the potential benefits and burdens accrue only to Ann. 
According to the "separateness of persons," individuals' lives have a separateness that renders it inappropriate to balance benefits and burdens that accrue to each person as if they accrued to a single life. ${ }^{36}$ It is therefore worthwhile to see how the proposed view handles a case that clearly contrasts intrapersonal and interpersonal tradeoffs, adapted from Voorhoeve and Fleurbaey: ${ }^{37}$

Intrapersonal versus Interpersonal Trade-Off Case: In this case, Ann and Bill will both soon go completely blind ( 0.65$)$ unless Tessa intervenes and selects one of the available treatments. There are two scenarios: one interpersonal and one intrapersonal.

Interpersonal Scenario: Treatment $A$ (interpersonal) will with fifty percent probability either give Ann an increase in well-being leading to full health (1) while ensuring Bill gains partial sight (0.8), or instead, with fifty percent probability, Ann will gain partial sight while Bill remains blind. Treatment $B$ will ensure that both Ann and Bill have partial sight.

Intrapersonal Scenario: Treatment $A$ (intrapersonal) will ensure that Bill has partial sight, while giving Ann a fifty percent chance of full health and a fifty percent chance of partial sight. Treatment $B$ will ensure that both Ann and Bill have partial sight. (See Table 7.)

Table 7. Final Utilities for Intrapersonal versus Interpersonal Trade-Off Case

\begin{tabular}{l|cc|cc} 
& \multicolumn{2}{|c|}{$\mathrm{S1}(0.5)$} & \multicolumn{2}{c}{$\mathrm{S2}(0.5)$} \\
& Ann & Bill & Ann & Bill \\
\hline $\begin{array}{l}\text { Treatment } A \\
\text { Interpersonal) }\end{array}$ & 1 & 0.8 & 0.8 & 0.65 \\
Treatment $B$ & 0.8 & 0.8 & 0.8 & 0.8 \\
\hline $\begin{array}{l}\text { Treatment } A \\
\text { Intrapersonal) }\end{array}$ & 1 & 0.8 & 0.65 & 0.8 \\
Treatment $B$ & 0.8 & 0.8 & 0.8 & 0.8
\end{tabular}

In Interpersonal Scenario there is no prospect for Bill to ever be better off than Ann. If Tessa selects $A$ then only Ann has a chance at being more advantaged, whereas Bill does not. Bill only has a chance of being disadvantaged. Tessa ought to select $B$ in this scenario. The proposed view respects the separateness of persons by being sensitive to some only bearing a potential burden in order for oth-

36 Voorhoeve and Fleurbaey, "Egalitarianism and the Separateness of Persons," 382.

37 Voorhoeve and Fleurbaey, "Egalitarianism and the Separateness of Persons," 387. 
ers to only receive a potential benefit. The proposed view respects the unity of the individual by requiring the selection of $A$ in Intrapersonal Scenario for Ann's sake, since the potential benefits and burdens only fall to her. Treatment $B$ is not permissible in Intrapersonal Scenario because there are no competing claims. By contrast, in Interpersonal Scenario there are competing claims because there is a conflict of interest ex ante. The competition between these claims favors $B$, because $A$ would involve making one person better off at another's expense. In making these contrasting judgments, the view respects the difference between the unity of the individual and the separateness of persons.

\section{CONCLUSION}

I have argued that when the interests of only one person are at stake, one ought to act out of a concern for their best expected interests. A pattern of outcomes that contains inequality does not itself constitute grounds for individual complaints of unfairness. I also argued that the type of risk that one is exposed to can affect the permissibility of selecting certain treatments. If individuals are exposed to independent risks, there is both a compelling prudential justification that can be offered that appeals to the separate futures of distinct individuals and there is an absence of competing interests, so that one does not have to balance competing claims on behalf of a better-off and a worse-off person. By contrast, I have also argued that when there are competing interests (either $e x$ ante or $e x$ post) then one has reason to avoid inequality that would arise because some are worse off to others' benefit. In sum, I have provided a competing claims account that guides how a decision maker ought to act in conflict of interest cases involving risk and also in cases of certainty. I have shown that this approach respects both the unity of the individual and the separateness of persons. ${ }^{38}$

Virginia Tech tmrowe@vt.edu

38 Versions of this article were presented at the University of Manchester and the University of Warwick. I would like to thank those present for their comments. I would also like to thank Keith Hyams, Chris Marshall, Michael Otsuka, Tom Parr, Bastian Steuwer, James Wilson, and two anonymous reviewers for this journal for their very helpful comments. Special thanks to Alex Voorhoeve, who gave very helpful comments on multiple drafts of this paper. Work on this article was supported by the British Arts and Humanities Research Council through grant AH/J006033/1. 


\section{REFERENCES}

Bovens, Luc. "Concerns for the Poorly Off in Ordering Risky Prospects." Economics and Philosophy 31 , no. 3 (November 2015): 397-429.

- "The Ethics of Making Risky Decisions for Others." In The Oxford Handbook of Ethics and Economics, edited by Mark D. White. Oxford: Oxford University Press, forthcoming.

Broome, John. "Equality versus Priority: A Useful Distinction." Economics and Philosophy 31, no. 2 (July 2015): 219-28.

Crisp, Roger. "In Defence of the Priority View: A Response to Otsuka and Voorhoeve." Utilitas 23, no. 1 (March 2011): 105-8.

Frick, Johann. "Contractualism and Social Risk." Philosophy and Public Affairs 43, no. 3 (November 2015): 175-223.

- "Uncertainty and Justifiability to Each Person." In Inequalities in Health: Concepts, Measures, and Ethics, edited by Nir Eyal, Samia A. Hurst, Ole F. Norheim, and Dan Wikler, 130-45. Oxford: Oxford University Press, 2013.

Greaves, Hilary. "Antiprioritarianism." Utilitas 27, no. 1 (March 2015): 1-42.

Kamm, Frances. Morality, Mortality Volume I: Death and Who to Save from It. Oxford: Oxford University Press, 1993.

Lange, Benjamin. "Restricted Prioritarianism or Competing Claims?" Utilitas 29, no. 2 (June 2017): 137-52.

Lazenby, Hugh. "Broome on Fairness and Lotteries." Utilitas 26, no. 4 (December 2014): 331-45.

McCarthy, David. “The Priority View." Economics and Philosophy 33, no. 2 (July 2017): $215-57$.

- "Utilitarianism and Prioritarianism II." Economics and Philosophy 24, no. 1 (March 2008): 1-33.

Nissan-Rozen, Ittay. "How to Be an Ex-Post Egalitarian and an Ex-Ante Paretian." Analysis 77, no. 3 (July 2017): 550-58.

Otsuka, Michael. "Prioritarianism and the Separateness of Persons." Utilitas 24, no. 3 (September 2012): 365-80.

Otsuka, Michael, and Alex Voorhoeve. "Equality versus Priority." In The Oxford Handbook of Distributive Justice, edited by Serena Oslaretti, 65-85. Oxford: Oxford University Press, 2018.

—. "Reply to Crisp." Utilitas 23, no. 1 (March 2011): 109-14. . "Why It Matters that Some Are Worse Off than Others: An Argument against the Priority View." Philosophy and Public Affairs 37, no. 2 (April 2009): 171-99. 
Parfit, Derek. "Another Defence of the Priority View." Utilitas 24, no. 3 (September 2012): 81-125.

Rowe, Thomas, and Alex Voorhoeve. "Egalitarianism under Severe Uncertainty." Philosophy and Public Affairs 46, no. 3 (Summer 2018): 239-68.

Scanlon, T.M. What We Owe to Each Other. Cambridge, MA: Harvard University Press, 1998.

Sen, Amartya. "Internal Consistency of Choice." Econometrica 61, no. 3 (May 1993): 495-521.

Temkin, Larry S. Inequality. Oxford: Oxford University Press, 1993.

Voorhoeve, Alex, and Marc Fleurbaey. "Decide as You Would with Full Information! An Argument Against ex ante Pareto." In Inequalities in Health Concepts, Measures, and Ethics, edited by Nir Eyal, Samia A. Hurst, Ole F. Norheim, and Dan Wikler, 113-28. Oxford: Oxford University Press, 2013.

."Egalitarianism and the Separateness of Persons." Utilitas 24, no. 3 (September 2012): 381-98.

- "Priority or Equality for Possible People?" Ethics 126, no. 4 (July 2016): 929-54.

Williams, Andrew. “The Priority View Bites the Dust?” Utilitas 24, no. 3 (September 2012): 315-31. 